\title{
Stage-structured predation regulates a cross-ecosystem resource subsidy
}

\author{
Jeff Wesner ${ }^{1,1}$ and Tyler Seidel ${ }^{2}$ \\ ${ }^{1}$ University of South Dakota \\ ${ }^{2}$ University of Minnesota College of Biological Sciences
}

May 5, 2020

\begin{abstract}
Organisms undergo substantial ecological changes throughout development, such as shifts in habitat use, trophic position, and predation risk. However, developmental variation is rarely considered in natural food webs. We manipulated fish predation to test the hypothesis that cross-ecosystem subsidies are regulated by stage-structured predation in a freshwater food web. Fish reduced the emergence of adult stages of aquatic insects to the terrestrial ecosystem by $85 \pm 0.04 \%$ (mean \pm sd DM) leading to a $\sim 40 \%$ reduction in terrestrial insectivorous spider abundance. By contrast, fish had weaker effects on larval aquatic insects, reducing dry mass by $63 \pm 72 \%$. These stage-specific effects were explained by a stage-structured food web in which fish ate similar prey taxa but different prey stages. Since organisms with complex life-histories are widespread, we suspect that this type of stage-structured predation, and its regulation of cross-ecosystem subsidies, is a common phenomenon beyond freshwater food webs.
\end{abstract}

\section{Hosted file}

REU_2017-ms_submitted.pdf available at https://authorea.com/users/299974/articles/429862stage-structured-predation-regulates-a-cross-ecosystem-resource-subsidy 